This is the peer reviewed version of the following article: Robinson, J. and Comerford, D.A. (2020), The Effect on Annuities Preference of Prompts to Consider Life Expectancy: Evidence from a UK Quota Sample. Economica, 87: 747-762, which has been published in final form at https://doi.org/10.1111/ecca.12326. This article may be used for non-commercial purposes in accordance with Wiley Terms and Conditions for self-archiving.

\title{
The Effect on Annuities Preference of Prompts to Consider Life Expectancy: Evidence
}

\author{
from a UK quota sample \\ Jenny Robinson \\ David A. Comerford*
}

\begin{abstract}
State-run pensions advice websites in the UK and the US recommend considering how long the pension needs to last and offer a life expectancy calculator for this purpose. Theories make conflicting predictions regarding the effect on annuities preference of following this recommendation. We asked a quota sample of over 2,000 UK residents to choose between an annuity or cashing out their pension. Immediately prior to choice, a random subset of participants were asked how long their retirement will last; others were asked what age they will live to; others were asked what age they will die by; and a control group was not asked to consider how long the pension needs to last. Asking about life expectancy reduced preference for annuities relative to the control condition. This research suggests that the reference to life expectancy on the UK's pension advice website exacerbates underannuitization.
\end{abstract}

Keywords: annuities; pensions; life expectancy; household decision making; mortality salience

JEL codes: D15, D84, D91

*Comerford: Economics Division and Behavioural Science Centre, Stirling Management School, Cottrell Building, FK9 4LA (email: david.comerford@stir.ac.uk) ORCID: 0000-0003-2611-9504. Robinson: Irrational Insights Ltd., EN9 2HJ (email: jenny@irrational-insights.com). 


\section{The Effect on Annuities Preference of Prompts to Consider Life Expectancy: Evidence from a UK quota sample}

\section{Introduction}

One of the largest and most consequential financial decisions that a person can be asked to make in the course of her life is how to decumulate the wealth in her private pension. Should you buy an annuity (a stream of income that is guaranteed for life) or take a cash lump sum? Because it involves pension wealth that has typically accumulated over the course of decades of contributions, the decision offers people the opportunity to walk away with more money than most will have seen in their lives up to that point. It is not merely the amount of money that makes the decision high stakes, however; a potential outcome is penury in old age. Further complicating matters, feedback on the quality of one's decision comes slowly, is difficult to evaluate and may only prove conclusive when it is too late to correct for the initial mistake.

The pensions decumulation decision warrants the attention of policy makers and pensions providers because longer lifespans and the rise of defined contribution pensions mean that increasing numbers of people worldwide will be charged with the task of making decumulation choices in the coming decades. Moreover, the international experience is that far fewer people choose to decumulate their pensions in the form of an annuity than would be predicted given the expected financial benefits of annuitizing (Benartzi, Previtero and Thaler, 2011; Duxbury, Summers, Hudson, and Keasey, 2013; Finkelstein and Poterba, 2004; Pashchenko 2013; O’Meara, Sharma \& Bruhn, 2015). This is termed the annuitization puzzle and various explanations have been posited to account for it, some rooted in the behavioural decision-making literature (Duxbury et al., 2013) ${ }^{\mathrm{i}}$. First there is an "illusion of wealth" effect 
whereby a cash lump sum is wrongly perceived to be more generous than the equivalent amount paid out each month as an annuity (Goldstein, Hirschfeld and Benartzi, 2016). Second, present-bias reduces annuities preference (Brown and Previtero, 2014; Schreiber and Weber, 2016). Third, Salisbury and Nenkov demonstrate in a series of studies a mortality salience effect, such that evoking the concept of death reduces preference for annuities (2016). Finally, it was found in a UK sample that removing the word "annuity" from the description of an annuities product increased preference for it by 16 percent (FCA, 2014).

The current research tests how annuities preference is affected by a prompt to consider how long retirement will last. This question is of practical interest because a recommendation to consider "how long your pension needs to last" is currently broadcast on the UK's state-run Pension Wise website (Figure 1a) and a prompt to consider "how long you might live" appears on the US Social Security public advice website (Figure 1b). Notwithstanding that it is currently in use, we can find no tests of the effect on decumulation decisions of prompting consideration of retirement duration. This dearth of published evidence is particularly striking because prior literatures offer contradictory predictions on the likely effect of the prompt. Before setting out our study, let's briefly consider the predictions of theory. Both the US and the British websites prompt people to consider their retirement duration and offers them a life expectancy calculator for that purpose. Based on the prior literature, we identify three independent effects of this treatment: an attention effect that predicts an increase in annuities preference; an information effect that predicts heterogeneous effects on annuities preference; 
and a mortality salience effect that predicts a decrease in annuities preference.

\section{How long your money needs to last}

You'll need to think about how to make the money you've got last for the rest of your lifetime.

You can use the Office of National Statistics calculator to estimate your life expectancy. This can help you plan how long your pension may need to last - but lifestyle choices and other factors may affect how long you live.

\section{! Taking too much of your pension money in early retirement could mean you don't have enough for later.}

Figure 1a: Screenshot from the UK public information website of the prompt to consider how long your pension needs to last (Pension Wise, 2019)

Social Security

Benefits Planner | Life Expectancy

Home Retirement Disability Survivors Calculators

When you are deciding when to start receiving retirement benefits, one important factor to take into consideration is how long you might live.

According to data we compiled:

- A man reaching age 65 today can expect to live, on average, until age 84.0.

- A woman turning age 65 today can expect to live, on average, until age 86.5.

And those are just averages. About one out of every three 65 -year-olds today will live past age 90, and about one out of seven will live past age 95 .

Want to know your life expectancy? You can use our simple Life Expectancy Calculator

Figure 1b: Screenshot from the US public information website of the prompt to consider life expectancy (Social Security Administration, 2019) 
We find in a national quota sample of over 2,000 Britons that the effect of following the recommendation to consider life expectancy is to reduce preference for annuities. Given the various and contradictory predictions of theory we did not consider it feasible that this study would trace through the various mechanisms through which the life expectancy prompt has its effect. We do, however, offer some post hoc analyses on this question and present some descriptive data in this regard. Notably, we ask respondents to rank five considerations that Beshears et al. (2014) found to be important when decumulating pension savings. This analysis shows that prompting respondents to estimate the age they will die by systematically altered priorities; it reduced the importance placed on two attributes on which annuities are strong (Income Security and Income Certainty) relative to the control condition and increasing the importance placed on an attribute on which annuities are weak, bequest motives.

This research contributes to several literatures that are of interest to public economists. First, it contributes to the growing literature on the annuities puzzle. O’Dea and Sturrock (2018; 2019) suggest that underannuitization might be partly explained by systematic underestimation of life expectancy and predict that informing people of their life expectancy could contribute towards redressing the bias against annuities (ibid, 2019, p. 20). The literature is conflicting regarding this prediction, however. Beshears et al. exposed people to mortality tables, which set out objective survival probabilities for people of the same age and sex as the respondent, and found a reduction in preference for annuities (2014). In what follows we find that prompting people to estimate their own life expectancy reduces preference for annuities, echoing the results of Beshears et al. (2014). We conclude that, contrary to the prediction of O'Dea and Sturrock (2019), consideration of life expectancy actually reduces preference for annuities. Second, it contributes to the literature on economic decision making by raising the prominence of a psychological theory that has not previously 
been considered to have meaningful economic consequences: Terror Management Theory (e.g. Arndt and McCabe, 2016; Burke, Martens, and Faucher, 2010; Greenberg and Arndt, 2011). We highlight Terror Management Theory because it alone correctly and unambiguously predicted the results observed in the current research (Salisbury and Nenkov, 2016). With hindsight, the results of this specific study might be explained by mechanisms unrelated to Terror Management Theory; still we consider Terror Management Theory to offer predictions that warrant the attention of economists and policymakers working on endof-life topics. Third, this study contributes to the literature on the role for randomized controlled trials in policymaking (e.g. Deaton and Cartwright, 2018). Our research documents a case in which a public policy intervention appears to backfire: we doubt that anyone working on the UK and the US advice websites suspected that recommending consideration of life expectancy would exacerbate the problem of underannuitization. The current research is therefore an instructive case study.

In the next section we briefly outline some theories that offer conflicting predictions regarding the recommendation to consider retirement duration. Section 3 details our experimental design. Section 4 reports the results. In Section 5 we conclude.

\section{Theory}

Here we review three literatures that offer predictions regarding the effect of the recommendations to consider retirement duration and life expectancy. The first literature we consider is that on the gap between subjective life expectancy and objective life expectancy. There is a robust finding in the literature on subjective life expectancy that younger people underestimate their life expectancy, but that this tendency reduces with age; this pattern has been reported for the US (Elder, 2013), Australia (Wu, Stevens and Thorp, 2015) and the UK 
(O’Dea and Sturrock, 2018). This downward bias in anticipated lifespan has been hypothesized to explain part of the annuities puzzle (O’Dea and Sturrock, 2019). O'Dea and Sturrock (2019) suggest that an intervention that increases the accuracy of subjective life expectancy will increase preference for annuities. In a recent paper they endorsed the life expectancy information on the US Social Security webpage as a means to attenuate the bias against annuities and advocated a "role for larger policy interventions to inform households about the length of the retirement that they might have to fund" (O'Dea and Sturrock, 2019, p. 20). Their suggestion has been tested. In a stated preference study, Beshears, Choi, Laibson, Madrian, and Zeldes (2014) found that preference for annuities was altered following exposure to objective life expectancy information; contrary to O'Dea and Sturrock's prediction, however, annuities preference was reduced. In any case, Beshears et al. explained the observed reduction with reference to the same underlying causal mechanism as O’Dea and Sturrock (2019): they speculated that exposure to the objective life expectancy information caused respondents to update their subjective life expectancy (Beshears et al., 2014 p.13).

Whereas Beshears et al, (2014) tested the effect of presenting life expectancy information, our contribution is to test the effect of merely asking people to estimate their life expectancy. It is possible that prompting people to articulate their expected age of death causes them to generate a more considered life expectancy estimate than if the question of life expectancy is left implicit. Relatedly, the estimate that people come to can be influenced by the question by which life expectancy is elicited (Payne, Sagara, Shu, Appelt and Johnson, 2013; Comerford and Robinson, 2017). Thus, the mere fact of being asked to estimate life expectancy could prompt retrieval of information that would alter perceived life expectancy and so, in line with 
the predictions of O’Dea and Sturrock (2019) and Beshears et al. (2014), shift preference for annuities.

A second relevant literature for predicting the effect of the recommendation is that on limited attention and salience (e.g. DellaVigna, 2009). Prompting consideration of a factor immediately prior to choice would be expected to make it cognitively accessible. In a situation where people face trade-offs and must weigh up many different factors, an attribute that enjoys increased cognitive accessibility would be expected to receive increased decision weight (e.g. Biehal \& Chakravarti, 1983; Johnson, Haubl and Keinan, 2007; Weber, Johnson, Milch, Chang, Brodscholl, and Goldstein, 2007; Wyer, 2008).

The prompt to consider retirement duration draws attention to an unambiguously relevant consideration: all else being equal, the expected value of an annuity is increasing in retirement duration. To the extent that the annuities puzzle is explained by misweighting of cues in the decision criterion (e.g. attaching weight to use of the term "annuity" to describe the product as found in FCA, 2014), we would expect the prompt to increase preference for annuities. In short, annuities preference is expected to increase due to the attention effect.

The third literature we have found that speaks to this question is that on Terror Management Theory and mortality salience (Salisbury and Nenkov, 2016). Terror Management Theory posits that the mere thought of death evokes defensive responses, which include an aversion to death-related stimuli (e.g. McCabe and Arndt, 2016). Salisbury and Nenkov reasoned that "by forcing people to think about dying, the annuity decision makes people's mortality salient, motivating them to defend against this threat by avoiding the annuity option" (2016, p. 418). In line with this prediction, prompting mortality salience was found to reduce preference for annuities. In one of their studies a marketing brochure was manipulated so that an annuity was 
described either as making payments "each year you live" or as making payments "each year you live until you die"; the addition of the three words "until you die" reduced annuities preference from 36 percent to 26 percent (Salisbury and Nenkov, 2016, p. 421). The US and UK websites make mortality salient by offering a life expectancy calculator (Figures 1a and 1b) and, in the US case, by making explicit reference to "how long you might live" (Figure 1b). Terror Management Theory predicts that these prompts to consider life expectancy will reduce preference for annuities.

We have briefly reviewed three literatures that imply three distinct effects of the prompts that are currently in use on US and UK pensions advice websites. These three effects identified by the literature operate independently of one another. Also, the attention effect and the mortality salience effect work in opposite directions. Whether the net effect of the recommendations presented on the US and UK websites is to increase or decrease annuities preference is a question on which theory is conflicted. It is best answered empirically.

\section{Study}

\subsection{Overview}

This study elicits a stated preference, in common with most of the literature that seeks to understand the decision making processes that underpin the annuitization decision (e.g. Beshears et al., 2014; FCA, 2014; Goedde-Menke, Lehmensiek-Starke, and Nolte, 2014; Goldstein et al., 2016; Salisbury and Nenkov, 2016; Schreiber and Weber, 2016).We ask a quota sample of Britons to choose between taking their pension in cash and taking it as an annuity that pays a guaranteed income each year for the rest of the recipient's life.

The Pension Wise prompt refers to two distinct concepts: how long the pension needs to last and life expectancy (Figure 1). An advantage of using a stated preference measure is that 
we could manipulate how explicitly we refer to life expectancy in our survey instrument. We test three alternative frames of the prompt: a frame that asks how long your retirement will last; a frame that asks what age you will live to; and a frame that asks what age you will die by.

We look to the UK for two reasons. First, the UK Pension Wise website currently uses the retirement duration prompt and so its population is the most policy relevant for assessing the effects of that prompt. A second reason why a UK quota sample is particularly instructive is that the UK's institutional environment relating to pensions has recently changed dramatically. It had been the case up to the early 2000s that the vast majority of UK pensions were de facto annuities; they were Defined Benefit pensions that guaranteed the recipient a portion of her salary for the rest of her life. Since then, workplace pensions have become Defined Contribution pensions (along the lines of $401 \mathrm{Ks}$ ), where workers and employers pay into a pot each month and at the end of the career the worker receives whatever wealth has accumulated. Up until 1995, annuitization of Defined Contribution pension pots was compulsory for the over 55 s and until 2015 , annuitization at age 75 was compulsory except under specific circumstances (Banks, Crawford and Tetlow, 2015). A series of "Pensions Freedom" reforms introduced in 2015 removed this annuitization requirement and gave retirees an option never previously available: to take their pensions in a full cash lump sum on reaching retirement (for details see Thurley, 2014; Banks, Crawford and Tetlow, 2015). Simultaneously, a policy of workplace pension automatic enrolment has seen a large increase in the number of UK citizens who will eventually face a pensions decumulation decision (Cribb \& Emmerson, 2016). To our knowledge, this is the first survey of pension decumulation preferences in the UK since the 2015 Pensions Freedom reforms.

\subsection{Methods}




\subsubsection{Participants}

A quota sample that was intended to match the characteristics of the UK population aged over $18(\mathrm{~N}=2096)$ undertook an online self-completion survey as the first section in a multi-survey questionnaire, on 14-16 June 2016. The sample was selected from Populus's proprietary panel of 130,000 UK adults. Quotas were set on age, gender and region based on the known profile of the UK from the 2012 National Readership Survey, a random probability face-toface survey conducted annually with 34,000 adults.

\subsubsection{Materials}

Participants were randomly allocated to one of four conditions (see Table 1). Three of these survey conditions opened with a question regarding how long the participant's money would need to last in retirement. The control condition asked how many years the respondent spent in formal education. The control condition was intended (1) to have no effect on annuities preference relative to the absence of a prompting question, (2) to make the duration of the survey similar across conditions and (3) to ensure that respondents in every condition are prompted to consider a span of years.

Table 1: Prompts Used in Each Survey Condition

\begin{tabular}{ll} 
Prompt & Survey Wording \\
\hline Control & I took part in formal education for a total of _ years \\
Retirement duration & I expect my retirement to last _ years \\
Live-to & I expect to live to age _ \\
Die-by & I expect to die by age _
\end{tabular}

Our dependent variable is choice between annuitization and encashment. The annuity product offered was a guaranteed income paid to an individual recipient that expires at death. The 
concept of an annuity was explained to participants using wording taken from the UK's Pension Wise website ${ }^{\mathrm{ii}}$ : Preference was elicited using the following question:

"[You said that you \{expect to live to $\mathrm{x} /$ expect to die by $\mathrm{x} /$ expect to have a retirement lasting x years/ completed x years of formal education $\}$.] Please assume that you are reaching retirement and have a defined contribution pension pot. Which of the following would you choose:

Guaranteed Income (annuity): You use your pot to buy an insurance policy that guarantees you an income for the rest of your life - no matter how long you live. You can take $25 \%$ of your pot as tax-free cash and buy an annuity with the other $75 \%$.

Take Cash: This can be done in either of two ways:

In Chunks: You can take smaller sums of money from your pot until you run out. Your 25\% tax-free amount isn't paid in one lump sum - you get it over time, or Take your whole pot in one go: You can cash in your entire pot $-25 \%$ is tax free, the rest is taxable.

Order effects were ruled out by randomising the presentation of the choice options. Radio buttons were not shown to participants until after a three-second lag set to ensure that the question was read fully before an answer was selected.

So as to promote external validity we deliberately did not specify how large a pension pot participants are decumulating. This contrasts with the most recent study on annuities preferences in the UK, which told participants that they had a pension pot of $£ 100,000$ (FCA, 2014). We decided not use this figure because it is far larger than the value of pension pots 
that the average UK resident can expect to decumulate. In 2012 the median pension pot held by those UK residents aged 55-64 who have DC pensions was $£ 25,000$ (ONS, 2014).

After reporting their pension choice, participants were asked to rank five attributes of retirement savings in order of importance when considering how they would use their pension pot from 1 (high) to 5 (low). These were Bequest, Income Security, Certainty, Flexibility and Control and the full descriptions, as shown to respondents, are reported in Table 2. These attributes were selected for inclusion because they were found to be important drivers of the decumulation decision in Beshears et al. (2014). This attribute-ranking task also offers exploratory data on whether the prompts alter people's pension decumulation motives. The order in which the attributes were presented was randomised to rule out order effects.

Table 2: Pension Attributes that were ranked for importance by respondents

Pension Attribute

Flexibility

Control

Security

Certainty

Bequest
Wording used in Survey

Being able to access variable amounts of money

Being able to choose your own investments to create an income from your pension pot

Knowing you won't run out of money because your income is fixed for the rest of your life

Knowing exactly what your income will be in future

Being able to leave money from your pension pot to your surviving relatives or other beneficiaries

We closed our survey instrument by asking if respondents had a defined contribution pension pot and, if so, to report its approximate size on an ordinal scale. In addition to the data we collected, the market research company that recruited the sample provided us with data on 
respondent characteristics. These included income (measured by income bands on an ordinal scale), marital status, age, gender, whether the respondent has children, respondent's religious affiliation, whether the respondent has a chronic illness and socioeconomic group (derived from ONS methodology, see note to table 3 for a more complete description).

\section{Table 3: Sample Means by Condition}

Variable

Control duration

Live-to

Die-by

DV: Proportion choosing

annuities

0.73

0.69

$0.67 *$

$0.64 * *$

Respondent characteristics collected in our survey:

Age

47.29

47.97

48.76

47.60

Does not have DC pension

0.42

0.42

0.42

0.45

Doesn't know if DC pension

0.03

0.05

0.04

0.03

Already drawing DC pension

0.17

$0.22 * *$

0.20

0.21

Size of pension pot (if known)

$£ 30 \mathrm{k}-£ 40 \mathrm{k}$

$£ 30 \mathrm{k}-£ 40 \mathrm{k}$

$£ 30 \mathrm{k}-£ 40 \mathrm{k}$

$£ 30 \mathrm{k}-£ 40 \mathrm{k}$

Doesn't know pension pot size

0.24

0.25

0.25

0.22

Respondent characteristics provided by market research company:

Female

0.52

0.50

0.49

0.50

Income band

$£ 28 \mathrm{k}-£ 34 \mathrm{k}$

$£ 28 \mathrm{k}-£ 34 \mathrm{k}$

$£ 28 \mathrm{k}-£ 34 \mathrm{k}$

$£ 28 \mathrm{k}-£ 34 \mathrm{k}$

Did not report income

0.06

0.06

0.08

0.07

Socioeconomic Group

2.47

2.38

2.45

2.43

Has children

0.71

0.75

0.71

0.76

No religious affiliation

0.36

0.41

0.41

0.38

Married or cohabiting

0.60

0.60

0.61

0.55

No chronic illness

0.75

0.77

0.75

0.74

$\mathrm{n}=524$

$\mathrm{n}=525$

$\mathrm{n}=526$

$\mathrm{n}=521$

Notes:

DC pension refers to a Defined Contribution pension, the type for which the annuities vs. encashment choice is relevant.

Socioeconomic Group is categorized using a measure employed by the British Office for National Statistics. It employs an algorithm that, on the basis of education, occupation, and housing characteristics, categorises census respondents into one of six social grades (UK Geographics, 2017). In the data we received, the two lowest social grades were pooled to create group 1, which accounts for 27 percent of the sample; and the two highest social grades were pooled to create group 4, which accounts for 26 percent of the sample.

$*$ differs from Control Condition at $p<.05, * *$ differs from Control Condition at $p<.01$

\subsubsection{Estimation Strategy}

Table 3 reports summary statistics of respondents by survey condition. Generally,

randomization was successful in delivering similar samples across the treatment and control 
conditions. In what follows, we first present the results of bivariate regressions that do not control for any other variables and we then report analyses from a richer model that controls for survey condition and all of the respondent characteristics reported in Table 3.

In our survey, we collected information on whether the participant has a DC pension (categorical data) and on the size of that pension (ordinal data). We also include this in our richer model. Our richer model does not include respondents' rankings of pension attributes because these rankings were systematically impacted by prompting condition. Were we to include pension attribute rankings in the model then the estimated effect of the prompts would be biased by collinearity.

\section{Results}

\subsection{The Effects of Prompts}

Figure 2 graphs the percentage of respondents choosing to annuitize by condition. It shows that annuitization was highest in the control condition and lowest in the die-by condition.

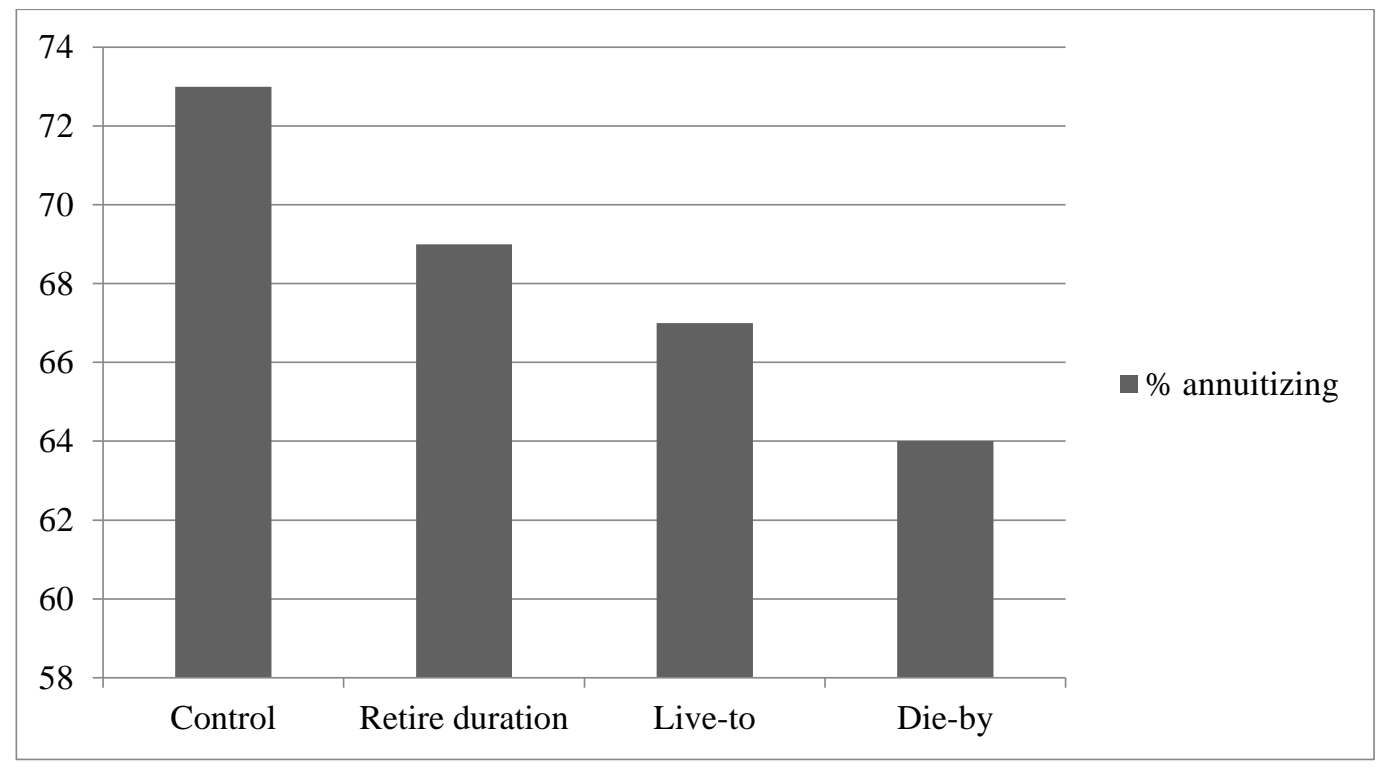

\section{Figure 2: Percentage choosing to annuitize by condition}

To understand the different effects of the prompts, we test the effect relative to the control condition of each prompt in turn. 
Table 4: Results of Binary Logistic Regression on Annuities Preference

\begin{tabular}{|c|c|}
\hline Retire duration prompt condition & -0.224 \\
\hline & $(0.138)$ \\
\hline Live-to prompt condition & $-0.298 *$ \\
\hline & $(0.137)$ \\
\hline Die-by prompt condition & $-0.410 * *$ \\
\hline & $(0.136)$ \\
\hline Age & -0.001 \\
\hline & $(0.004)$ \\
\hline Does not have DC pension & 0.028 \\
\hline & $(0.140)$ \\
\hline Doesn't know if DC pension & -0.400 \\
\hline & $(0.258)$ \\
\hline Already drawing DC pension & 0.105 \\
\hline & $(0.165)$ \\
\hline Size of pension pot (if known) & -0.036 \\
\hline & $(0.025)$ \\
\hline Doesn't know pension pot size & $0.787 * *$ \\
\hline & $(0.233)$ \\
\hline Female & -0.009 \\
\hline & $(0.097)$ \\
\hline Income band & 0.019 \\
\hline & $(0.024)$ \\
\hline Did not report income & -0.307 \\
\hline & $(0.302)$ \\
\hline Socioeconomic group & -0.027 \\
\hline & $(0.048)$ \\
\hline Has children & 0.184 \\
\hline & $(0.120)$ \\
\hline No religious affiliation & 0.052 \\
\hline & $(0.102)$ \\
\hline Married, cohabiting or civil & 0.188 \\
\hline & $(0.109)$ \\
\hline No chronic physical/ mental & 0.001 \\
\hline & $(0.116)$ \\
\hline Constant & $0.756^{*}$ \\
\hline & $(0.348)$ \\
\hline Observations & 2,096 \\
\hline
\end{tabular}

Notes: Standard Errors in parentheses

$*$ differs from Control Condition at $p<.05 ; * *$ differs from Control Condition at $p<.01$

Binary logistic regressions that do not control for any other variable show that preference for annuities was significantly lower in each of the two conditions that prompted consideration of life expectancy than in the control condition (die-by condition vs. control: $n=1045 ; b=-$ $.411, z=3.06, p=.002$; live-to condition vs. control: $n=1050, b=-.277, z=2.05, p=.040$ ). The retirement duration condition also shows lower preference for annuities than the control 
condition though this difference is not statistically significant (Retirement duration condition vs. control: $n=1049, b=-.210, z=1.54, p=.123$ ). Table 4 shows that these results are robust to the inclusion of controls.

\subsection{Robustness Checks}

We were not expecting that prompting people to consider life expectancy would reduce preference for annuities and so we first investigate the effect of our control condition, which prompted participants to report the number of years they spent in formal education. We cannot test the effect of the control condition relative to a no-prompt condition but one test that is available to us concerns the correlation between reported years of education and preference for annuities: if prompting people to consider the years they spent in education increases their preference for annuities then we would expect that this effect is stronger for those who spent longer in education. We find that this correlation coefficient is low and not statistically significant, $r=.04, t=.91, p=.36$. Our results do not look to be explained by our control condition increasing preference for annuities.

The above results include data from respondents who reported that they have already started claiming pension benefits $(n=419)$. These respondents are less likely than the rest of the sample to make a decumulation decision in the future and so, to deliver what might be considered a more policy-relevant estimate of the effect, we reran the model set out in Table 4 having dropped them from the sample. Again, none of the prompts show positive coefficients ( $n=1,677$; live-to: $b=-.288, z=1.92, p=.055 ;$ die-by: $b=-.490, z=3.31, p=.001$; retirement duration: $b=-.189, z=1.24, p=.215)$. 


\subsection{Post-Hoc Tests for Mechanism}

Recall that we asked respondents to rank five considerations that the previous literature suggests are important when decumulating pension savings. This allows us to explore whether the effect of the life expectancy prompt is to alter priorities and, if so, to reveal what considerations become prioritized in response to each prompt. We did not have specific hypotheses on how these considerations would be affected by the prompts and so these analyses are post hoc and should be considered exploratory.

Table 5: Percentage of respondents ranking attribute as most important, by condition

\begin{tabular}{lllll}
\hline & Control & Retire duration & Live-to & Die-by \\
\hline Income Security & 52 & 47 & 43 & 47 \\
Certainty & 26 & 29 & 28 & 22 \\
Control & 11 & 11 & 14 & 15 \\
Flexibility & 8 & 9 & 11 & 11 \\
Bequest motives & 3 & 4 & 4 & 5 \\
\hline
\end{tabular}

For these analyses, we tested the rank ordering of pension attributes in each of the prompting conditions compared with those in the control condition. We highlight three results from these analyses. The first is that there was a large degree of consensus across conditions on which considerations to prioritize (Table 5). In all conditions, Income Security, which was explained to respondents as “knowing you won't run out of money because your income is fixed for the rest of your life", was most likely to be ranked most important. In all conditions, Income Certainty, which was explained to respondents as "knowing exactly what your income will be in future", was next most likely to be ranked as the highest priority and was most likely to be ranked as second most important. In all conditions, Bequest, which was explained as "being able to leave money from your pension pot to your surviving relatives or other beneficiaries" was least likely to ranked as most important and was most likely to be ranked last in terms of importance. 


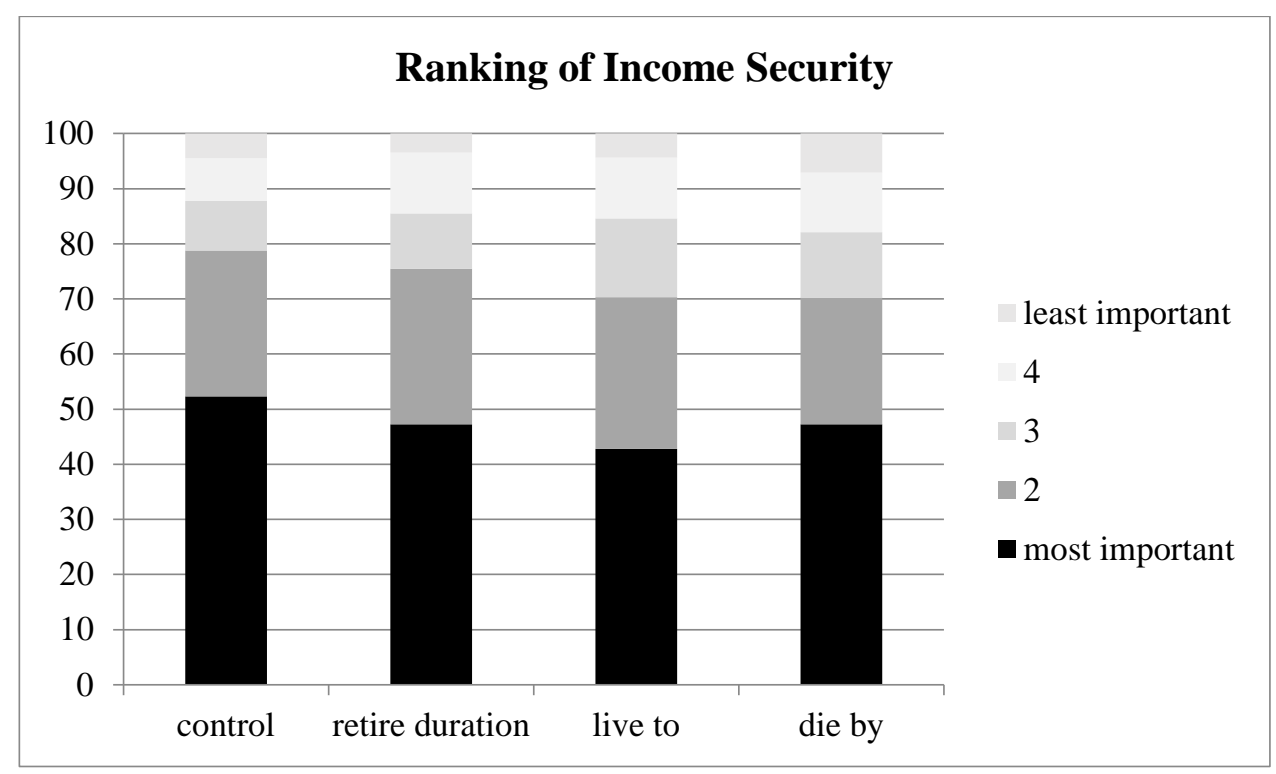

Figure 3: Ranking of Income Security in terms of importance by survey condition

The second result is that relative to the control condition there was a reduction in the degree to which Income Security was considered a priority in the three treatment conditions. A binary logistic regression of ranking Income Security highest shows that respondents in the control condition were significantly more likely to rank it highest than were those in any of the three treatment conditions $(n=2,096, z=2.60, p=.009)$. A non-parametric Kruskal-Wallis ranksum test (which tests not only whether Income Security was ranked first, but considers where it featured in each respondent's full rank ordering) delivers a similar conclusion: Income Security was ranked as less of a priority in each of the three prompting conditions than in the control condition. As depicted in Figure 3, the reduction is not large but was statistically significant in the die-by condition (rank sum $_{\text {die by }}=283,836.5$ vs. rank sum $_{\text {control }}=262,698.5$, chi-square $=6.30, p=.012)$ and the live-to condition $($ rank sum live to $=291,627.5$ vs. rank sum $_{\text {control }}=260,147.5$, chi-square $\left.=11.017, p<.001\right)$. The reduction was not statistically significant in the retirement duration condition (rank sum retire duration $=267,607.5 \mathrm{vs}$. rank sum $_{\text {control }}=283,117.5$, chi-square $\left.=2.729, p=.096\right)$. 
The third result is that the die-by frame most strongly altered respondents' priorities relative to the control condition (see Figure 4). Whereas the live-to and retirement duration conditions showed differences relative to the control condition only in the ranking of Income Security, the die-by condition also caused respondents to rank Certainty (knowing exactly what your income will be in the future) as less important relative to the control condition (rank sum die-by $=284348.50$ vs. rank sum $_{\text {control }}=262186.50$, chi-square $\left.=6.47, p=.011\right)$. It caused respondents to rank Bequest motives as more important than did those in the control condition $\left(\right.$ rank sum $_{\text {die-by }}=258,045.50$ vs. rank sum sontrol $=288,489.50$, chi-square $\left.=10.37, p=.001\right)$.

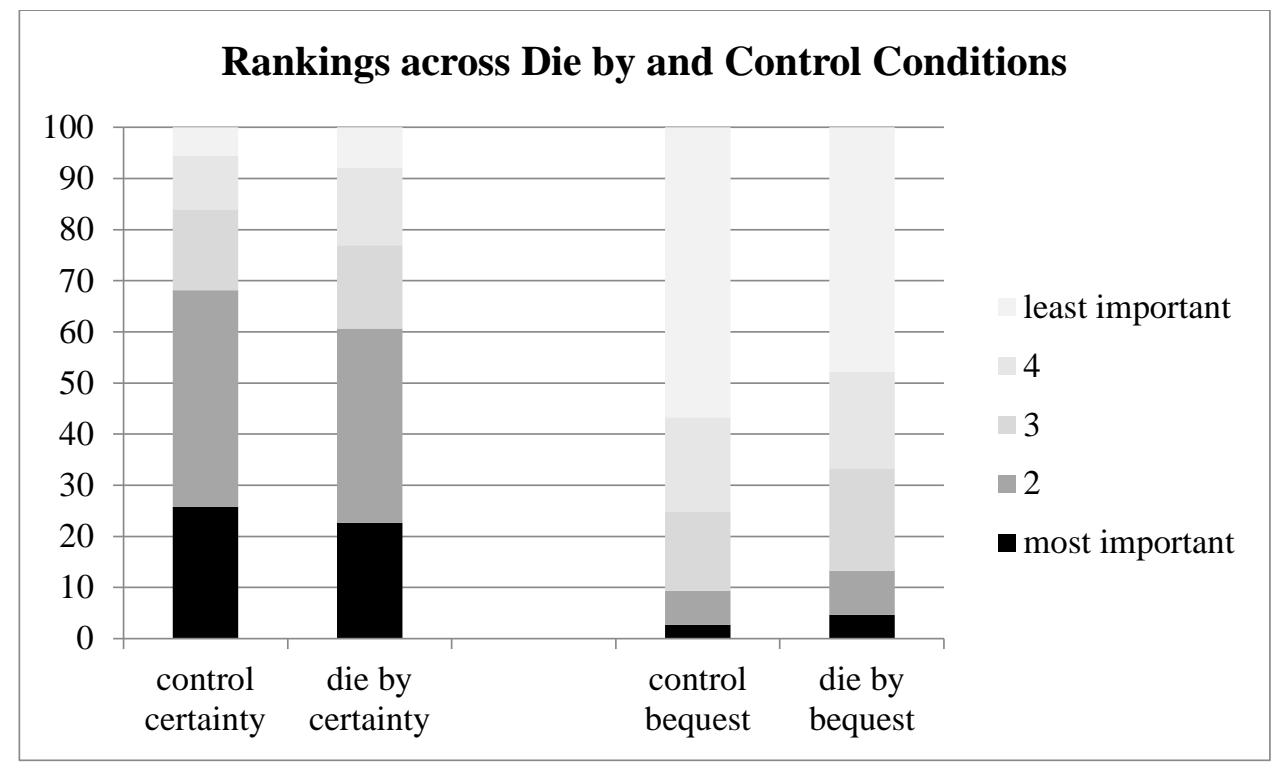

Figure 4: The Die-by frame resulted in Income Certainty being ranked less important and Bequest Motives being ranked more important relative to the control condition

These exploratory analyses suggest that prompting consideration of life expectancy has the effect of shifting priorities with regard to pension decumulation. This shift in ranking is sensibly related to the reduction in annuities preference reported above: those who were asked “what age will you die by?" ranked the attributes on which annuities are strong (income security, income certainty) as less of a priority than those in the control condition and ranked the attribute on which annuities are weak (bequests) as more of a priority than those in the 
control condition. It follows therefore that those who were asked "what age will you die by?" would value annuities less than do those in the control condition.

The reduction in preference for annuities is consistent with the prior literature (e.g. Beshears et al., 2014; Salisbury and Nenkov, 2016) and accords with the predictions of Terror Management Theory (Salisbury and Nenkov, 2016). However, our reading of the literature on Terror Management Theory did not lead us to clear predictions on which of the five pension attributes would become more or less a priority as a response to death-related stimuli. Also anonymous reviewers helpfully pointed out alternative mechanisms. Whereas Terror Management Theory posits that death-related thoughts trigger certain motivated responses (i.e. a shunning of death related stimuli), an alternative effect of considering one's own death might be to focus attention on one's legacy. To the extent that consideration of death causes people to care more about the bequest they leave behind, this could also account for our results. Furthermore, we cannot rule out that differences in subjective estimates of life expectancy across conditions drive the results, which is the mechanism proposed by O'Dea and Sturrock (2019) and Beshears et al. (2014). In this view, the mere act of estimating and reporting a life expectancy causes respondents to consider information that makes them less optimistic regarding their lifespan relative to the information that spontaneously comes to mind when making a pensions decumulation choice. Relatedly, if the process of estimating life expectancy causes people to perceive greater uncertainty regarding their lifespan than they had implicitly assumed then the perceived riskiness of an annuity would be greater and, at the margin, risk averse individuals would be expected to switch to the certain lump sum (Hu and Scott, 2007; Benartzi et al., 2011). Given these various potential mechanisms, we hesitate to implicate any one specific theory as driving our results. 


\section{Discussion}

\subsection{Overview of results}

The core result of this paper is that prompting people to consider their life expectancy causes them to become less likely to annuitize. Our post-hoc tests suggest that prompting consideration of life expectancy induces a shift in the importance that people place on various aspects of a pension.

\subsection{Limitations}

Before going on to consider some concrete recommendations that derive from our results, it is worth exploring the limitations of our study. We caution against taking the level of preference for annuities reported in this survey to be a forecast of annuities demand in the UK. Our survey necessarily left out some important factors that warrant research in their own right. Notably, we presented our participants with just two options - encashment or annuitization. There is an income drawdown alternative that we did not offer participants and it seems likely that more alternatives will be developed as the market evolves. Relatedly, the annuity product we presented was very basic. Joint annuities and annuities with survivor benefits are offered on the market, but we did not give our participants these options. Additionally, there are attributes of the annuities product that participants may have valued idiosyncratically that we did not measure: for instance, expectations of high inflation or low levels of institutional trust would be expected to reduce preference for annuities. Another factor that is particularly relevant to the UK is expectations regarding state pension provision, since current levels of state pension are relatively high by international standards. All of these factors add noise to the levels of preference reported in our data. It is important to note, however, that concerns regarding the absolute levels of preference for annuities reported in our survey do not trouble our conclusion that consideration of life 
expectancy reduces preference for annuities because this conclusion derives from differences across randomly assigned conditions.

\subsection{Conclusions}

At the outset of this research we had hoped to be able to direct policy makers from across the globe to the UK's Pension Wise site as a model on how to offset the biases that lead to underannuitization. The UK state was a pioneer in applying choice architecture (see Dolan, Hallsworth, Halpern, King, Metcalfe and Vlaev, 2012) and it seemed reasonable to expect that its state-run Pension Wise website, introduced as part of the Pensions Freedom reforms of 2015, harnessed this expertise. The key result from our study is that the prompt to consider how long a pension needs to last did not increase the likelihood of annuitizing. In the two conditions where the prompt made reference to life expectancy (just as the US and UK websites do), it significantly reduced preference for annuities relative to the control condition. Given the general finding from international studies that people are less likely to annuitize than is in their financial best interest, we conclude that these prompts are likely to exacerbate a pre-existing bias against annuities.

We draw two policy conclusions from our results: a specific one and a more general lesson. The specific conclusion we draw is that the recommendation to consider life expectancy should be removed from the Pension Wise website immediately pending further investigation of its effects. Our results are drawn from a quota sample of UK residents and hence should match well with population level data. On the basis of these results, we consider the Pension Wise website to be actively exacerbating the bias against annuities in the UK. We further suggest that the US Social Security Administration conducts a randomized controlled trial to test whether their prompt to consider life expectancy also reduces preference for annuities. 
The more general policy lesson of our research is that experimentation can add value even in situations where the outcome of an intervention might appear to be a foregone conclusion. This study brings to light a case where experts and economic theory aligned to suggest one result and experiments demonstrated the opposite result. Cormac O'Dea and David Sturrock are leading researchers who have published extensively on lifecycle savings in the UK and its relation to life expectancy (see for example Banks, O’Dea and Oldfield, 2010; Bozio, Laroque and O'Dea, 2017; Crawford and Sturrock, 2018; O'Dea and Sturrock, 2018 and O'Dea and Sturrock, 2019). In a recent paper they endorsed the life expectancy information on the US Social Security webpage as a means to attenuate the bias against annuities and advocated a "role for larger policy interventions to inform households about the length of the retirement that they might have to fund"' (O'Dea and Sturrock, 2019, p. 20). Our experiment is not alone in finding that the effect of prompting people to consider their life expectancy is contrary to what O'Dea and Sturrock hypothesized; Beshears et al. (2014) found that exposing respondents to mortality tables reduced annuities preference. Yet, neither we nor Beshears et al. (2014) had predicted that life expectancy information would reduce preference for annuities and neither we nor Beshears et al. (2014) can offer a decisive explanation for the observed result. In fact, had there been a policy debate prior to the implementation of the Pension Wise prompt, we would have endorsed O'Dea and Sturrock's theory-informed recommendation to prompt people to consider their life expectancy. Yet, the data shows us humbled. The current research therefore highlights an important case: one where the consensus of experts is proven wrong by experimentation.

Finally, we note that there did exist a theory that predicted the opposite results to those hypothesized by O'Dea and Sturrock (2019) but acknowledge that it is unsurprising that it has slipped the attention of economists. Terror Management Theory is a floridly psychological theory that lies well outside the realm of standard economic theory but it may yet be shown to 
offer important predictions for economists and policymakers working on topics related to endof-life.

\section{References}

Ameriks, J., Caplin, A., Laufer, S., \& Van Nieuwerburgh, S. (2011). The joy of giving or assisted living? Using strategic surveys to separate public care aversion from bequest motives. The Journal of Finance, 66(2), 519-561.

Banks, J. Crawford, R., \& Tetlow, G. (2015) Annuity choices and income drawdown: Evidence from the decumulation phase of defined contribution pensions in England. Journal of Pension Economics and Finance, 14 (4), 412-438.

Banks, J., O’Dea, C., \& Oldfield, Z. (2010). Cognitive function, numeracy and retirement saving trajectories. The Economic Journal, 120(548), F381-F410.

Benartzi, S., Previtero, A., \& Thaler R.H.,(2011) Annuitization Puzzles. Journal of Economic Perspectives, 25 (4), 143-164.

Beshears, J., Choi, J.J., Laibson, D., Madrian, B.C. \& Zeldes, S.P. (2014) What makes annuitization more appealing? Journal of Public Economics, 116, 2-16.

Biehal, G., \& Chakravarti, D. (1983). Information accessibility as a moderator of consumer choice. Journal of Consumer Research, 10(1), 1-14.

Bozio, A., Laroque, G., \& O’Dea, C. (2017). Discount rate heterogeneity among older households: a puzzle?. Journal of Population Economics, 30(2), 647-680.

Brown, J. R., \& Previtero, A. (2014). Procrastination, present-biased preferences, and financial behaviors. Unpublished Manuscript, University of Illinois at Urbana-Champaign and University of Western Ontario.

Burke, B. L., Martens, A., \& Faucher, E. H. (2010). Two decades of terror management theory: A meta-analysis of mortality salience research. Personality and Social Psychology Review, 14(2), 155-195.

Comerford, D. A., \& Robinson, J. (2017). Die-by Framing both Lengthens and Shortens Life: Further Evidence on Constructed Beliefs in Life Expectancy. Journal of Behavioral Decision Making, 30(5), 1104-1112.

Crawford, R., \& Sturrock, D. (2018). Should generations differ in their wealth accumulation?.

Cribb, J., \& Emmerson C. (2016). What happens when employers are obliged to nudge? Automatic enrolment and pension saving in the UK (No. W16/19). Institute for Fiscal Studies.

Deaton, A., \& Cartwright, N. (2018). Understanding and misunderstanding randomized controlled trials. Social Science \& Medicine, 210, 2-21. 
Dolan, P., Hallsworth, M., Halpern, D., King, D., Metcalfe, R., \& Vlaev, I. (2012).

Influencing behaviour: The mindspace way. Journal of Economic Psychology, 33(1), 264277.

Duxbury, D., Summers, B., Hudson, R., \& Keasey, K. (2013). How people evaluate defined contribution, annuity-based pension arrangements: A behavioral exploration. Journal of Economic Psychology, 34, 256-269.

FCA (2014) Does the framing of retirement income options matter? A behavioral experiment - rims-framing-experiment.pdf. Available: https://www.fca.org.uk/static/fca/documents/rimsframing-experiment.pdf [Accessed: 7/11/2016].

Finkelstein, A. \& Poterba, J. (2004) Adverse Selection in Insurance Markets: Policyholder Evidence from the U.K. Annuity Market. Journal of Political Economy, 112 (1), 183-208.

Goedde-Menke, M., Lehmensiek-Starke, M., \& Nolte, S. (2014). An empirical test of competing hypotheses for the annuity puzzle. Journal of Economic Psychology, 43, 75-91.

Goldstein, D.G., Hershfield, H.E. \& Benartzi, S. (2016) The Illusion of Wealth and Its Reversal, in NA - Advances in Consumer Research Volume 43, eds. Kristin Diehl and Carolyn Yoon, Duluth, MN : Association for Consumer Research, pp. 136-141.

Greenberg, J., \& Arndt, J. (2011). Terror management theory. Handbook of theories of social psychology, 1, 398-415.

Hu, W. Y., \& Scott, J. S. (2007). Behavioral obstacles in the annuity market. Financial Analysts Journal, 63(6), 71-82.

Johnson, E. J., Häubl, G., \& Keinan, A. (2007). Aspects of endowment: a query theory of value construction. Journal of experimental psychology: Learning, memory, and cognition, $33(3), 461$.

Lockwood, L. M. (2012). Bequest motives and the annuity puzzle. Review of economic dynamics, 15(2), 226-243.

McCabe, S., \& Arndt, J. (2016). The Psychological Threat of Mortality and Its Implications for Tobacco and Alcohol Misuse. In Neuropathology of Drug Addictions and Substance Misuse (pp. 327-336). Academic Press.

O'Dea, C., \& Sturrock, D. (2018). Subjective expectations of survival and economic behaviour (No. W18/14). Institute for Fiscal Studies.

O'Dea, C., \& Sturrock, D. (2019). Survival pessimism and the demand for annuities (No. W19/02). Institute for Fiscal Studies.

O’Meara, T., Sharma, A. \& Bruhn., A. (2015). Australia's Piece of the Puzzle-Why Don't Australians Buy Annuities? Australian Journal Of Actuarial Practice 47(3). 47-57.

ONS (2014) Accessing Defined Contribution (DC) Pension Savings. Available: http://webarchive.nationalarchives.gov.uk/20160105195434/http://www.ons.gov.uk/ons/rel/pe 
nsions/pensions-short-stories/accessing-defined-contribution--dc--pension-savings/styaccesing-defined-contribution--dc--pension-savings.html [Accessed: 26-6-17].

Pashchenko, S. (2013) Accounting for non-annuitization. Journal of Public Economics, 98, 53-67.

Payne, J. W., Sagara, N., Shu, S. B., Appelt, K. C., \& Johnson, E. J. (2013). Life expectancy as a constructed belief: Evidence of a live-to or die-by framing effect. Journal of Risk and Uncertainty, 46(1), 27-50.

Pension Wise (2016) Available: https://www.pensionwise.gov.uk/guaranteed-income [Accessed: 20/07/2016]. https://web.archive.org/web/20171124120510/https://www.pensionwise.gov.uk/en/makingmoney-last

Salisbury, L. C., \& Nenkov, G. Y. (2016). Solving the annuity puzzle: The role of mortality salience in retirement savings decumulation decisions. Journal of Consumer Psychology, 26(3), 417-425.

Schreiber, P. \& Weber. M. (2016) Time inconsistent preferences and the annuitization decision. Journal of Economic Behavior and Organization, 129, pp. 37-55.

Social Security (2019). https://www.ssa.gov/planners/lifeexpectancy.html.

Thurley, Djuna (2014). Pensions: income drawdown. London, House of Common Library.

Weber, E. U., Johnson, E. J., Milch, K. F., Chang, H., Brodscholl, J. C., \& Goldstein, D. G. (2007). Asymmetric discounting in intertemporal choice: A query-theory account. Psychological Science, 18(6), 516-523.

Wyer, R. S. (2008). The role of knowledge accessibility in cognition and behavior. Handbook of consumer psychology, 4, 31-76.

Acknowledgments: The authors thank Cormac O’Dea and Simon McCabe for helpful comments. The authors have no interests or funding to report.

\footnotetext{
i There are also explanations for the annuities puzzle that accord with the standard economic framework. These include bequest motives (e.g. Lockwood, 2012) and a precautionary motive to have a lump sum to cover healthcare costs (e.g. Ameriks, Caplin, Laufer and Van Nieuwerburgh, 2011). Here we focus on behavioural explanations because our goal is to test whether it is possible to redress an apparent bias against annuities.

ii Pension Wise includes tax implications in the descriptions of taking cash on their "pension pot options" webpage so we replicated this. Our one deviation from the Pension Wise presentation is that its description of annuities does not mention tax implications, whereas our survey's description of annuities does. We added this information (that people can take a tax-free $25 \%$ lump sum from their annuity) because it is true and also so as to insure that descriptions of both options were equally informative with regard to tax implications. The description of tax implications of annuities was taken verbatim from elsewhere on the Pension Wise website.
} 